\title{
Uma análise antropológica sobre a cosmologia da comunidade quilombola de Lagoinha de Cima: entre santos, "arrumações" e seres não-humanos
}

\author{
Sonia Regina Lourenço \\ Departamento de Antropologia \\ Universidade Federal de Mato Grosso \\ Danielli Katherine Pascoal da Silva \\ Mestre em Antropologia Social \\ Universidade Federal de Santa Catarina
}

Resumo: $O$ presente artigo é resultado de uma pesquisa etnográfica na comunidade quilombola Lagoinha de Cima, localizada em Chapada dos Guimarães, Mato Grosso. Buscamos compreender sua cosmologia através da análise das narrativas sobre práticas de "arrumação" e "benzeção" que são modos de intervenção mágica capazes de atingir os corpos humanos, vegetais e animais. Além destas, abordamos a agência dos santos e outros seres nãohumanos. Neste contexto, a noção de religião mostra-se limitada ao entendimento das experiências identificadas, pois as dimensões cosmológicas não se reduzem à institucionalidade do religioso. A contribuição deste estudo consiste tanto em descrever a ontologia subjacente à organização social quanto em elucidar os enquadres explicativos nativos sobre as transformações políticas e sociais vivenciadas por esta comunidade.

Palavras-chave: identidade étnica; cosmologia; quilombola; seres nãohumanos. 


\title{
An anthropological analysis about a cosmology in a rural black community: among saints, "arrumações" and non-humans beings
}

\begin{abstract}
This article is the result of ethnographic research in a black community called Lagoinha de Cima, located in Chapada dos Guimarães, in the State of Mato Grosso. We seek to understand their cosmology through the analysis of narratives about practices of "arrumação" and "benzeção", which are understood as modes of magic intervention capable to affect human, plant and animal bodies. Furthermore, we analyze the agency of the saints and other nonhuman beings. In this context, the notion of religion is considered as limited to understand the experiences above mentioned, because the cosmological dimensions in this case are not reduced to the institutionality of the religious. The contribution of this research lies both in describing the ontology underlying social organization as well as in elucidating the native explanatory frameworks about the social and political transformations experienced by this ethnic group.

Keywords: ethnic identity; cosmology; black communities; non-humans beings.
\end{abstract}

\section{Un análisis antropológico sobre la cosmología en una comunidad rural negra: entre santos, "arrumações" y seres no humanos}

Resúmen: Este artículo es el resultado de una investigación etnográfica en la comunidad negra de Lagoinha de Cima situada en Chapada Dos Guimarães, en el Estado del Mato Grosso. Se trató de entender su cosmología a partir de las narrativas sobre las prácticas del "arrumação" y del "benzeção", que son entendidas como métodos de intervención mágicas capaces de afectar cuerpos humanos, animales y vegetales. Además, se analizó la capacidad de acción de los seres no humanos y de los santos. En este contexto, se considera la noción de religión limitada a la comprensión de las experiencias identificadas, pues las dimensiones cosmológicas no se reducen a la institucionalidad de lo religioso. La contribución de este estudio consiste tanto en la descripción de la ontología subyacente a la organización social, como en la aclaración de los encuadres explicativos nativos sobre las transformaciones sociales y políticas experimentadas por este grupo étnico.

Palabras clave: identidad étnica; cosmología; comunidades negras; seres no-humanos. 
Este artigo é resultado da pesquisa desenvolvida entre julho de 2012 e dezembro de 2013 na comunidade quilombola Lagoinha de Cima, que desde 2005 é reconhecida pela Fundação Cultural Palmares (FCP, Ministério da Cultural), como comunidade remanescente de quilombo, processo que implicou tanto no conhecimento - pela população local - desta categoria jurídica, que os identifica como sujeitos de direitos, quanto na renomeação da associação de moradores de Pequenos Produtores Rurais para Comunidade Negra Rural Quilombola. Nesta localidade de Chapada dos Guimarães, há duas comunidades: Lagoinha de Cima e Lagoinha de Baixo, que se auto identificam como grupos étnicos distintos, mas compartilham um território tradicional cuja ocupação remonta à descendência comum dos antigos escravos dos engenhos de São Romão e Abrilongo ${ }^{1}$.

Conforme o Relatório de Caracterização Sócio-Histórica e Antropológica Associação Negra Rural quilombola de Lagoinha de Baixo, de Chapada dos Guimarães elaborado em 2007², estes engenhos datam do século XVIII implicando em mais de 200 anos da presença destas populações. As histórias narradas em Lagoinha de Cima indicam que a sua formação como comunidade não é oriunda de um quilombo ao modelo de Palmares, decorrente de um núcleo de escravos fugidos. Em Lagoinha de Cima fala-se de uma "senhoria" que libertou os negros, possibilitando a sua permanência nestas terras.

Associam ao seu território uma cosmologia feita de santos, seres nãohumanos, tais como: boitatá, troá, curupira, lobisomem e também de "benzeções" e "arrumações", que entrelaçam sentidos de pertencimento étnico. A inexistência de um templo religioso, bem como de uma vinculação religiosa específica, indicou que as relações entre os planos visível e invisível constitutivos da socialidade nesta comunidade não se conformavam à institucionalidade do religioso circunscrito em doutrinas (MALUF, 2011). Assim, a opção pelo conceito de cosmologia se deve não estritamente ao fato de que a religião quase não aparece na linguagem local, mas principalmente porque permite compreender estes modos de pensamento como práticas que articulam criativamente os saberes herdados de seus ancestrais às novas experiências sociais.

O entendimento de que essas diferentes formas de classificar o mundo são modos entre os quais não se pode estabelecer uma ordenação hierárquica, se desenvolveu, à medida que os antropólogos experimentaram um distanciamento reflexivo de seu mundo. As formas de classificação das

\footnotetext{
${ }^{1}$ A pesquisa de campo que resultou neste artigo teve recursos do projeto de pesquisa Performances, narrativas e musicalidades quilombolas na Chapada dos Guimarães (MT). Realizado pelo edital o02/2012/FAPEMAT/CNPq, Programa de Infra-Estrutura para Jovens Pesquisadores Programa Primeiros, Projetos - PPP - FAPEMAT. Período de execução: 09/2011- 04/2015; e do projeto de Extensão: Patrimônio cultural e saberes tradicionais quilombolas de Mato Grosso-MT. Edital PROEXT/MEC-SESU, 201, coordenados pela Prof ${ }^{\mathrm{a}} \mathrm{Dr}^{\mathrm{a}}$ Sonia Regina Lourenço, Departamento de Antropologia e do Programa de Pós-Graduação em Antropologia Social da UFMT. Parte das reflexões deste artigo são resultados do Trabalho de Conclusão de Curso de SILVA, Danielli Katherine Pascoal. Cosmologia quilombola: entre arrumações, benzeções e seres não-humanos. 2014. (Graduação em Ciências Sociais) - Universidade Federal de Mato Grosso.

2 SILVA, Renata Bortoletto \& GIANOTTI, Simone. Relatório de Caracterização Sócio-Histórica e Antropológica Associação Quilombola Comunidade Negra Rural Lagoinha de Baixo, Chapada dos Guimarães (MT). Instituto de Colonização e Reforma Agrária (INCRA), Superintendência Regional de Mato Grosso SR/13, Cuiabá, MT, março de 2007.
} 
ACENO, Vol. 3, N. 6, p. 71-86. Ago. a Dez. de 2016. ISSN: 2358-5587.

Cosmologias, territorialidades e políticas de quilombolas e de povos tradicionais (dossiê).

sociedades não ocidentais, por exemplo, não resultam de uma indigência intelectual, mas de uma diferença em relação às realidades para as quais são dirigidas. De acordo com Lévi-Strauss (1989) o pensamento selvagem concentra-se nas propriedades sensíveis e o pensamento científico nas propriedades conceituais.

Esse aporte etnográfico estimulou o desenvolvimento de reflexões sobre as categorias utilizadas pela antropologia para descrever outros universos culturais. E nesse percurso, a antropologia fez das culturas estudadas contraexemplos críticos da cosmologia ocidental (WAGNER, 2010), orientandose pela ideia radical de que "não há mundo pronto para ser visto, um mundo antes da visão, ou antes da divisão entre o visível (ou pensável) e o invisível (ou pressuposto) que institui o horizonte de pensamento" (VIVEIROS DE CASTRO, 2002a, p. 123).

Inspirada nesta perspectiva, o termo narrativizações proposto por Vania Cardoso (2007) possibilita uma abordagem que trata o ato de narrar como prática que constitui o evento narrado e o imaginário social. Neste caso, a relevância antropológica da presença dos seres não-humanos, nas narrativas contadas em Lagoinha de Cima, está tanto em seu potencial ontológico de "realizar esse possível como virtual" e "multiplicar o nosso mundo" (VIVEIROS DE CASTRO, 2002a, p. 132), quanto em seu potencial simbólico de expressar perspectivas sobre as relações sociais vivenciadas, conectando os sujeitos entre si e ao seu território.

\section{Os santos no oratório}

É muito provável que o pesquisador não seja capaz de perceber seus equívocos comunicativos - ou, mais precisamente, a comunicação como tradução e equívoco - no momento em que os diálogos são tecidos, mas se os, percebe pode apreendê-los do ponto de vista crítico e abstrair das ações que desencadeou, aspectos significativos das concepções locais. Note-se que equívoco aqui, não é sinônimo de erro, pois a questão não está entre o certo e o errado. Considerando a tradução como indissociável da comunicação humana, o equívoco é um deslocamento produtivo de perspectiva, capaz de ampliar o espaço imaginado entre linguagens e mundos em contato (VIVEIROS DE CASTRO, 2004).

Aqui o equívoco pode ser ilustrado pela frustração de uma expectativa pessoal: a busca por uma religião e uma igreja. Intrigada com a ausência de um templo religioso em Lagoinha de Cima, me questionava sobre as razões de tal situação e, durante uma entrevista, incomodada com o silêncio que insistia em reaparecer, lancei uma pergunta à Dona Vanilde: "Vocês têm alguma igreja aqui?" Ao que ela respondeu com um olhar reticente: "Não aqui não tem, já até pensamos em construir... mas o padre às vezes aparece aí, faz uma reza, como diz, uma missa, né?”.

O silêncio retomou seu lugar no diálogo, e percebi que a pergunta causoulhe certo constrangimento. Madalena, sua nora, acrescentou em tom justificativo: "Mas a gente acredita em santo, Dona Vanilde conta que tinha bastante festa de santo aqui, no tempo dos antigos"3. Dona Vanilde, interlocutora fundamental à elaboração deste trabalho, já havia contado sobre

3 Observações da pesquisa de campo realizada em dezembro de 2012. 
as festas de santo do "tempo dos antigos", no entanto, a questão feita por mim deu ênfase a algo não enfatizado por elas. A expressão de Madalena soou como uma resposta ao que imaginava ser para mim um signo de religiosidade: a existência de uma igreja.

A relação intelectual estabelecida entre os sujeitos da pesquisa é constantemente testada na conversa, onde se observa que não há uma adequação direta entre os significados da antropóloga e das interlocutoras, e é nesta diferença que o equívoco é produtivo e possibilita a emergência de outros entendimentos. Dona Vanilde seguiu até a cozinha para preparar um café e o assunto da conversa teve outros rumos.

Percebi como afirma Viveiros de Castro que "A 'arte da antropologia', [...] é a arte de determinar os problemas postos por cada cultura, não a de achar soluções para os problemas postos pela nossa" (2002a, p. 117). A ausência de igreja não se constituía em problema para eles, este era um problema que precisavam explicar aos outros, interessados em igrejas. O cotidiano das rezas desde o "tempo dos antigos" nunca aconteceu no interior de igrejas, pois este espaço religioso não existia na comunidade. A sua prática se dava nas festas de santo, na benzeção, e em períodos como a quaresma, quando as pessoas transitavam por todas as casas realizando rezas.

Observei que a cosmologia em Lagoinha de Cima caracteriza-se por um conjunto de relações, cuja noção de religião ou mesmo de religiosidade popular, seriam incapazes de compreendê-las. Concordo aqui com Oscar Saéz (2009, p. 23) de que o adjetivo popular guardaria consigo "mais ou menos explícita a crença na originalidade e pureza das religiões, a convicção de que sua verdade deve-se encontrar nas formas discretas de um livro sagrado ou de uma doutrina oficial, e não na prática perenemente desviante do povo fiel”. As práticas identificadas não são, portanto ações desviantes de uma religião oficial.

Os santos não estão incluídos na categoria de seres não-humanos, pois sua agência é caracterizada por qualidades que mais os aproximam do humano do que do seu oposto, uma vez que a não-humanidade neste contexto está associada principalmente ao aspecto monstruoso e aterrorizante. Os santos não aparecem, por exemplo, como intermediários de uma relação entre humanos e uma divindade superior, esta inclusive raras vezes apareceu nas narrativas ouvidas. Os santos são agentes, pois intercedem nas relações dos humanos entre si na resolução de seus problemas. Por isso, a devoção a eles tem relação direta com suas qualidades específicas em função de determinadas necessidades, tais como a cura de doenças, a resolução de conflitos familiares e a proteção espiritual contra seres não-humanos, tais como o troá, o boitatá, o lobisomem e a curupira.

Os santos aparecem como o motivo de festanças, em virtude do seu dia especial ou de uma contraprestação à dádiva recebida. Estas festas estão associadas ao "tempo dos antigos", onde se desfrutava de um território no qual todos "viviam juntos", como disse o Sr. João Fidélis, cunhado de Dona Vanilde, "era um tempo em que a terra era de uso comum". O "viver juntos" possibilitava a existência de mais de cem pessoas no território, hoje dispersas em bairros na cidade de Cuiabá e na área urbana de Chapada de Guimarães em razão da expropriação territorial, empreendida em fins da década de 1970. A memória das festas de santo apresenta-os como o centro de um espaço de realização 
coletiva, manifesta nas rezas, no "muxirum" 4 , nas cantorias de cururu5 e danças de siriri $^{6}$ e catira ${ }^{7}$.

Hoje a presença dos santos é marcada pela ausência destes espaços de realização coletiva. As práticas coletivas quase cessaram após o despejo marcado pelo "gradeamento" das terras, impossibilitando cada vez mais a continuidade do plantio das roças, das plantas terapêuticas, assim como das manifestações artísticas ligadas à devoção aos santos. O "gradeamento" é uma ameaça constante que gera temor em razão da violência sofrida.

Certa ocasião, Dona Vanilde interrompeu uma entrevista para levar-me ao quarto onde todos os santos estavam guardados em um armário, quando retirou São Benedito, e mostrou-me os demais santos. Afirmou que a razão de guardálos era protegê-los, pois "as pessoa hoje já não respeita muito, aí quando preciso venho eu busco eles aqui dentro"8. Quando retornaram à comunidade, após o despejo, os santos foram mantidos guardados "pra não quebrar". A alusão, portanto à "quebra dos santos" não me parece ser restrita à quebra das imagens, ela simboliza o rompimento forçado de um conjunto de práticas que estavam imbricadas e que foram fragilizadas, mas não eliminadas, desde a expulsão até a retomada territorial.

Contou-me ainda que antes da expropriação havia um oratório em sua casa. O oratório é o lugar dos santos e das velas para realização das rezas, e movimenta tanto o contato entre santos e pessoas quanto o intercâmbio de conhecimentos entre as rezadeiras. As imagens dos santos, não são matéria de fetiches do imaginário popular, sua relevância consiste na agência que a sua presença possui, ou nas palavras de Saéz "Os santos são reais não porque as lentes de Hubble os tenham localizado sentados sobre alguma nuvem galáctica, mas porque são matéria de interesse" (2009, p. 214-215).

Ao fim deste diálogo arrisquei sugerir que os santos poderiam retomar seu oratório. Dona Vanilde posteriormente retirou os santos do armário e reabriu o oratório na sala de sua casa.

4 O "muxirum" é uma categoria nativa que significa mutirão. Os muxiruns eram realizados coletivamente no plantio e colheita das roças, na limpeza dos terrenos das casas e nas festas de santo.

5 Cururu é uma manifestação musical, comum na região de Mato Grosso, tocada por homens com os instrumentos: viola de cocho e ganzá.

${ }^{6}$ O Siriri é a dança feita em pares que acompanha o cururu (OSÓRIO, 2012, p. 237).

$7 \mathrm{E}$ a catira é descrita localmente como um ritmo tocado por violeiros e dançada por pares de homens e mulheres que batem as palmas das mãos e sapateiam.

${ }^{8}$ Este diálogo realizado em dezembro de 2012 está registrado como nota de campo. Tratava-se de uma conversa que desenvolvi com Dona Vanilde, e fui surpreendida por sua atitude, em mostrar o lugar onde os santos estavam guardados. 


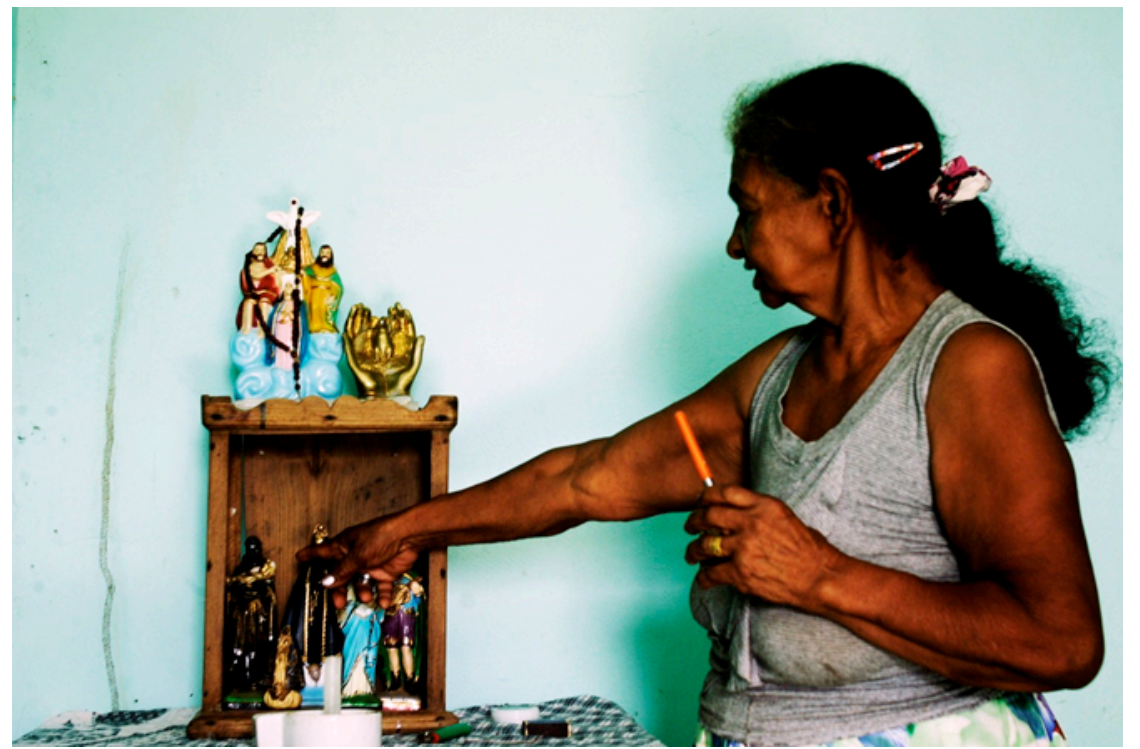

Foto: Dona Vanilde em sua residência, Lagoinha de Cima, 06/04/2013. Foto: Sonia R. Lourenço, arquivos da pesquisa.

Se Favret-Saada (2005) destaca a importância da antropóloga deixar-se afetar em campo e perceber que há uma densidade nas experiências compartilhadas entre os sujeitos da pesquisa maior do que propriamente na gravação de uma entrevista, acrescentaríamos que assim como nós transformamos e repensamos conceitos e perspectivas, os "nativos" também experimentam esta afetação.

A retomada do oratório pelos santos, a partir da atitude de Dona Vanilde, demonstra que a relação estabelecida com o outro, neste caso, com as pesquisadoras da universidade cria novos espaços de interlocução, particularmente quando estas relações são agenciadas por eles em um contexto de reivindicação pelo território tradicional ao serem reconhecidos pelo Estado brasileiro como sujeitos de direitos, conforme o Artigo 68 do Ato das Disposições Constitucionais Transitórias (ADCT 68) da Carta Constitucional de 1988, "Aos remanescentes das comunidades dos quilombos que estejam ocupando suas terras é reconhecida a propriedade definitiva, devendo o Estado emitir-lhes os títulos respectivos”.

\section{Seres não humanos e devir monstruoso}

A circulação de seres não-humanos em Lagoinha de Cima faz parte do mundo no qual as experiências destes sujeitos se configuram. Compartilhando de uma natureza monstruosa, tendem a se manifestar de modo surpreendente como "assombração" causando temor às pessoas. Entre eles identificou-se o troá, a curupira9, o boitatá e o lobisomem.

A ida à determinadas localidades muito distantes das residências como o "sumidouro", uma espécie de túnel com quedas d'água por onde passa o rio Lagoinha, ou a caminhada em horários noturnos, especialmente nos períodos de quaresma, é evitado. O sumidouro é um lugar onde as “porcariadas” se

\footnotetext{
9 Os dados obtidos acerca desta figura não humana, a curupira, são insuficientes para uma discussão antropológica. Portanto, sua menção está limitada ao registro como um dos seres identificados, sobre o qual não elaboramos nenhuma consideração mais específica.
} 
ACENO, Vol. 3, N. 6, p. 71-86. Ago. a Dez. de 2016. ISSN: 2358-5587.

Cosmologias, territorialidades e políticas de quilombolas e de povos tradicionais (dossiê).

manifestam. Este é um adjetivo comumente utilizado para nomear os seres nãohumanos.

O troá é descrito como um ser invisível que possui um pé único de vidro. É uma figura andrógina cujo corpo é feito metade homem e metade mulher. Sua mão e seu modo de andar são semelhantes ao humano, todavia, distingue-se pelo umbigo que é descrito como uma tocha de fogo que emana um odor mal cheiroso, semelhante ao cheiro da cobra cascavel e de enxofre, estas características denunciam a sua aproximação.

A sua aparição é relacionada, por exemplo, à ruptura das relações de evitação entre compadres ${ }^{10}$. A noção de "mistura" entre parentes considerados muito próximos, como o intercurso sexual ou casamento entre primos cruzados, denota o desrespeito ao código de parentesco onde uma relação íntima entre primos cruzados é compadres é interdita. O desrespeito à estas interdições têm como consequência a aparição monstruosa do troá. Dona Vanilde disse que a mistura é uma prática "do povo do olho d'água", informando que lá isto é permitido enquanto aqui não é. No entanto, em um de seus relatos, contou como a interdição foi rompida por duas pessoas de sua comunidade: entre sua sogra (cujo marido já havia falecido) e seu próprio compadre. A evitação de tais relações não implica em sua não ocorrência.

A aparição do troá quando há transgressão desta proibição, pode ser compreendida, como uma síntese da natureza marginal desta atitude, uma vez que a pessoa assume duas posições contraditórias numa mesma relação: 0 compadrio e a conjugalidade. A aparição de seres monstruosos, ou mais especificamente, a transformação corporal relacionada a transgressões de relações de parentesco é recorrente entre os povos indígenas, onde "o campo do parentesco e o campo da humanidade são igualmente coextensivos" (COELHO de SOUZA, 2004, p. 26).

A comunhão carnal entre compadres denota a emergência de uma condição não-humana sinalizada pela manifestação do troá. Neste caso, os transgressores não se transformam, mas experimentam a visão do horrendo e com isso, a ameaça de morte pelo bicho.

Se na narrativa apresentada, o surgimento do troá é relacionado à quebra de uma interdição sexual e à uma relação matrimonial, sua existência envolve um conjunto de relações muito mais amplas. Ele é um ser envolvido em concepções que definem suas qualidades e as condições de sua manifestação. Todavia, mais que um símbolo no sentido de Geertz como metáfora de princípios ordenadores das relações sociais (1989) ele é a expressão da potência desta ontologia na qual tanto a agência quanto o pensamento é atribuído a outros seres, de modo que, sinaliza ser a perspectiva uma capacidade não exclusiva aos humanos.

Para compreender ainda as características acionadas na descrição do troá, considero a percepção delineada por Turner (2005) a respeito das figuras monstruosas, relevantes à análise. Para este autor o caráter monstruoso age como um estímulo à reflexão, uma vez que "a monstruosidade da configuração dá relevo a seus elementos" (TURNER, 2005, p. 151). A aparência andrógina do troá, cujo corpo é duplo homem/mulher, o coloca numa condição ambígua “[...] de vez que não são nem uma coisa nem outra; ou podem ser as duas; ou podem não estar lá, nem cá” (idem, p. 142).

1o Para uma compreensão mais aprofundada ver RADCLIFFE-BROWN (1982, p.126; 2013). Não há espaço neste texto para desenvolver uma análise mais ampla sobre as relações de evitação e de jocosidade nesta comunidade. 
Sua fisionomia compõe-se também de outros elementos: um pé de vidro e odores de enxofre e cascavel. O vidro é um objeto frágil, a cascavel uma cobra peçonhenta e traiçoeira, características imputadas às práticas de desrespeito as concepções morais locais. A aparência do troá é uma composição a partir de elementos presentes no mundo sensível que serve também à metaforização de relações sociais desejadas e repelidas, uma expressão possível da ciência do concreto, nos termos de Lévi-Strauss, que se faz por meio da especulação do mundo sensível em termos de sensível (LÉVI-STRAUSS, 1989).

As vivências narradas não estão contidas na experiência passada, elas transbordam os supostos contornos espaço-temporais, na medida em que o ato de narrar é uma prática de elaboração da experiência, onde a própria narrativa constrói o mundo em percepções e ressignificações sobre o vivido: "A experiência ou o evento deixa de ser a origem da narrativa, a evidência que autoriza o discurso, para ser aquilo sobre o qual o 'conhecimento' e os ‘significados' são produzidos” (CARDOSO, 2007, p. 320).

Outra situação na qual o troá se manifesta é a transformação da terra em propriedade privada marcada pelo "gradeamento". O troá vem de Serra Abaixo em virtude do aumento populacional e da queima das roças dando lugar às cidades. Serra Abaixo abrange tanto as cidades abaixo do Rio Manso, quanto as comunidades circunvizinhas como Lagoinha de Baixo e um bairro de Chapada dos Guimarães: o Olho D’água. O troá busca habitar lugares que possuem roças e mata nativa. A narrativa informa que nessas condições de perda do território, o troá se sente ameaçado e anda pelas matas buscando um esconderijo.

Assumindo como premissa analítica que "o significado de um signo não é intrínseco, mas função do discurso em que se encontra inserido e de sua estrutura" (CARNEIRO DACUNHA, 2009, p. 239), elaboramos uma reflexão que considere o troá no contexto das experiências e narrativas que sua presença evoca.

Assim, o troá é também identificado como um bicho que ataca as pessoas, nas palavras de Dona Julita ele "é do capeta". Quando sua presença é identificada um símbolo chamado "cinco salomão" deve ser feito no chão para proteção e uma vela benta acendida. Este símbolo consiste num triângulo equilátero com a ponta semi-aberta e dois triângulos menores cada um em uma de suas faces laterais.

A origem deste símbolo é atribuída aos conhecimentos recebidos dos mais antigos. O troá é um ser temido e por consequência, evitado, postura semelhante à que se deve ter em relação a duas ações condenáveis: relações incestuosas entre compadres e apropriação individual das terras cuja consequência é o enfraquecimento das práticas culturais que lhe são significativas. O troá por isso, “[...] não é unívoco, mas multivocal, uma molécula semântica com muitos componentes" (TURNER, 2005, p. 149) a partir da qual esbocei as duas dimensões identificadas no curso da pesquisa de campo.

O boitatá possui o tamanho de um homem, cujo corpo é feito de lombrigas. Durante a metamorfose cresce até a parte superior de seu corpo pender em direção ao chão. Quando uma pessoa o encontra, deve fugir, caso contrário, ele a matará. Sua transformação monstruosa é associada à inversão da ordem familiar, onde um filho assassina a própria mãe. Quanto ao lobisomem, sabe-se apenas que é um homem e durante o período da quaresma transforma-se em lobisomem e além de atacar humanos, alimenta-se de defuntos, galinhas e 
porcos, mas uma descrição mais detalhada de sua transformação não foi tematizada pelas narrativas até a elaboração deste artigo.

O boitatá e o lobisomem são efeitos de uma metamorfose monstruosa, a mutação de corporalidade humana à uma corporalidade não-humana é desencadeada pela ocorrência de comportamentos reprovados moralmente pela comunidade. Os dados coletados em campo não permitiram fazer considerações mais profundas sobre ambos, mas indicam questões interessantes, tal como a condição virtual de um possível nos termos pensados por Deleuze e Guattari (1995).

O devir é pensado enquanto vir a ser, ao qual, os homens solteiros e que vivem solitários estão nessa condição do possível. Seria apressado dizer que esse devir monstruoso do lobisomem ou do boitatá, passa necessariamente por uma perspectiva que vê a si mesmo como humano e seus parentes como presas. $\mathrm{O}$ valor analítico da noção de devir está em perceber o deslizamento entre a condição humana e a potência monstruosa, considerando ainda que tais seres ocupem uma zona de indiscernibilidade, pois não são absolutamente monstros, mas humanos que poderão sofrer uma transformação transitória.

No caso do boitatá a sua existência é ambígua, manifesta e latente: é um ser que assombra as pessoas e que quando aparece tem o poder de matá-las, um ser que qualquer ser humano que assassinar sua mãe poderá nele se transformar. Um ponto interessante da reflexão de Deleuze e Guatarri é a consideração dos devires-animais como "perfeitamente reais" (1995, p. 15), o que exprime a experiência com os seres não-humanos que se movimentam em Lagoinha de Cima.

A presença destes seres como significativos para o universo de referências afectivas e perceptivas das pessoas da comunidade se manifesta na relação entre suas concepções morais e as práticas cotidianas, indicando possíveis transformações em decorrência das mudanças provocadas a partir do processo de expropriação territorial. Dada a recorrente afirmação do desaparecimento destes seres em função dos "tratores, do gradeamento", considero que tais significados foram refletidos a partir das transformações no processo de reterritorialização da comunidade, cujo espaço foi reduzido ao mínimo, impossibilitando a circulação dos humanos e tudo o que constitui suas relações sociais: práticas terapêuticas, seres não-humanos, festas de santo, roças, brincadeiras, danças e casamentos.

Sem recair no "pessimismo sentimental" (SAHLINS, 1997) é impossível ignorar as consequências da espoliação territorial. Todavia, ainda que pressões sejam exercidas, e falando mais na "resistência da cultura" do que em uma "cultura da resistência", as narrativizações (CARDOSO, 2007) destes sujeitos correspondem ao não esquecimento, de recuperar lugares de fala, objetivados por este curto relato etnográfico das experiências compartilhadas entre eles.

\section{Benzeção e "arrumação"}

As práticas de benzeção e de "arrumação" são atribuídas às pessoas mais próximas como os parentes próximos e às pessoas distantes, consideradas de fora da comunidade. Assim, o feitiço, por outro lado, prática considerada indesejável parece apontar para uma relação de alteridade, muito embora as pessoas que praticam a cura por meio das benzeções e arrumações podem ser identificadas como feiticeiras. Dona Vanilde afirmou certa vez: "dizem que sou 
feiticeira, porque sei das coisas, mas eu não ligo”, consideração que explicíta uma posição liminar do humano, que se define a cada experiência em relação aos efeitos que seus conhecimentos produzem. Em Lagoinha de Cima, ninguém se diz feiticeiro e ser acusado de sê-lo é uma forma de acentuar tensões e conflitos internos ou até mesmo potencializar conflitos com outrem "fora da comunidade".

Esta ambiguidade nos remete à pesquisa realizada por Liliane Porto (2007) no Vale do Jequitinhonha, onde identifica dois padrões de discurso coexistentes: o primeiro mobilizado para aqueles de 'fora' que expressa a feitiçaria como uma realidade passada relacionada à escravidão, e o segundo, manifesto para pessoas mais íntimas, que narra a feitiçaria como ato ordinário e cotidiano.

Em Lagoinha de Cima, a arrumação e a benzeção não são identificadas como eventos extraordinários, como quando se trata da aparição dos seres nãohumanos. Aqui há uma indistinção entre natureza e sobrenatureza em que não se ignora a mediação direta de agentes tais como animais ou acidentes, apenas articula a ela uma intervenção que subjaz as aparências de determinados acontecimentos.

As práticas locais de "arrumação" e benzeção são expressas na linguagem como um meio de explicação dada pelos nativos à pesquisadora, no entanto, não se encaixam em rígidas definições, pois o conceito se expande junto com a experiência de cada pessoa afinal "[...] o social é, em suma, muito mais amplo do que as explicações do social [...]” (SAÉZ, 2009, p. 215).

As narrativas que explicitam as categorias benzeção e "arrumação" as relacionam aos problemas de saúde e às situações conflituosas entre pessoas ou famílias, internas e externas à comunidade. Ambas são reputadas como ações de intervenção sobre os corpos humanos, vegetais e animais, cuja diferença é marcada pelo contexto de sua realização.

Assim, embora a benzeção apareça relacionada às práticas de cura, também está associada à produção de adversidades. Como por exemplo, benzer a plantação de um desafeto, impossibilitando o crescimento e o florescimento, ou um objeto que pertença a uma determinada pessoa a fim de provocar-lhe males físicos, ou ainda agir para produzir desde doenças que afeta os órgãos do corpo até os estados emocionais de tristeza e desânimo profundo. Tem-se uma concepção na qual é possível afetar outrem a partir de conhecimentos sobre um plano da socialidade, que é vivido coletivamente, mas que apenas alguns podem manipular.

Vinculada a benzeção, a “arrumação" não é uma prática determinada ontologicamente como boa ou má, ela é circunstancial. A mesma pessoa que prejudicou alguém pode livrar outra de uma "ofensa de bicho", isto é, o ataque de algum animal peçonhento. Por meio da benzeção ou da "arrumação", além de curar a ferida provocada, pode-se causar a morte do bicho responsável pelo ferimento.

Estas práticas são homólogas e não idênticas. Elas diferem no seguinte ponto: quando empreendida para prejudicar alguém, a benzeção é comumente associada às palavras, cuja motivação íntima produz determinados efeitos, como é o caso do mau agouro, isto é, "jogar praga" em alguém, enquanto a "arrumação" envolve a utilização de objetos em rituais específicos. Aqui, a palavra possui "a força ilocucionária” de que fala Austin (1990), em que dizer é 
ACENO, Vol. 3, N. 6, p. 71-86. Ago. a Dez. de 2016. ISSN: 2358-5587.

Cosmologias, territorialidades e políticas de quilombolas e de povos tradicionais (dossiê).

fazer o mundo. E assemelham-se quando o objetivo é auxiliar determinada pessoa: manipulam concomitantemente palavras e objetos em ritos.

As histórias contadas em Lagoinha de Cima, se apresentam em fragmentos articulados em função dos significados emergentes no curso da performance narrativa e se conectam às relações que os sujeitos narradores têm com as pessoas envolvidas nos eventos contados. Segue uma narrativa onde Dona Vanilde, conta duas histórias sobre seu tio Manezinho, a primeira em que realiza "ruindade" e a segunda em que faz uma benzeção salvando-a do veneno de uma cobra peçonhenta:

Dona Vanilde: É, que é o irmão da minha mãe. Ele caçava briga demais. Aí né, quando foi por fim, ele pôs até uma lacraia assim na perna dela. Ele cortava perna de vaca, cortava tudo com facão...

Eu: Mas, pra quê que ele cortava?

Dona Vanilde: De ruindade, que ele era ruim. Ele ia na roça, tem um lá o Juliano que planta arroz, ele pegou, ele foi lá, quando Juliano chegou na roça, ele já tinha ido lá benzer o arroz dele tudinho. Esava virando cacho, aí ele falou pra mim: 'ólha aquele chifrudo'. Num falava o nome dele, falava chifrudo. 'Ele foi lá na minha roça, foi lá e benzeu meu arroz, acabou meu arroz, agora eu tenho que trabalhar para comprar arroz, para dar de comer aos meus filhos...'

Eu: Como que é benzer o arroz?

Dona Vanilde: É uma coisa assim, só que ele tinha uma oração de São Jacó, né? Do livro de São Cipriano.

Eu: São Cipriano? É uma oração que ele fazia?

Dona Vanilde: Aham. É uma oração e ele benzia, com cobra ele matava só com benzeção. Ele aprendeu no livro, que ele sabia ler. Esse um menino meu, Agnaldo, achou ele na oração, mas ele não viu. Esse dia estava ele e o Messias daqui mesmo da Chapada, um falando para o outro assim: 'Se esse lá não trabalhar para mim, ele não terá nada'. Aí ele falou também: 'Se ele não trabalhar para mim ele não vai ter nada'. E o guri estava lá, ele estava com doze anos.

Eu: O Agnaldo?

Dona Vanilde: O Agnaldo, escutou tudinho. Chegou lá em casa e contou tudinho, $e$ eles não viu ele. Ele viu o livro e falô: 'Mãe, naquele livro tem isso, isso, isso, só de ruindade, só de fazer mal para os outros. Que ele já sabia lê, só de fazer mal para os outros. E ele fazia mesmo. Óia uma vez eu fui ofendida de bicho, lavava roupa pra ele, eu fui apanhar minha roupa lá, e bem assim na beira da estrada tinha uma lixeira, aí cavoucou o Benedito, ele passou na minha frente, quando eu passei, sentia aquele negócio na perna e falei: 'Dito, um trem mordeu minha perna', ele falou: 'Daí é cupim, cupinzão ele morde'. Aí cheguei em casa não tinha negócio de luz elétrica, apanhei fósforo, ascendi a lamparina e ah! O sangue já estava correndo e a perna estava desde tamanho, já [Fez sinal com a mão mostrando que a perna estava inchada].

Eu: A perna da senhora?

Dona Vanilde: A cobra já tinha picado, aí o Bento estava lá na casa do Juliano. Aí ele falou: 'Mãe, o que que aconteceu com a senhora?' Falei: Uma cobra, fui apanhar roupa lá no, na velha Maria, estava lá secando, que lavava minha roupa e a dele lá também. Aí ele falô: 'Vou até lá pra ver Manezinho, para benzer'. Aí já estava de noite, aí ele falou "hoje só vou fazer uma oraçãozinha e só".

Eu: Então, o Manezinho também benzia picada de cobra, essas coisas...

Dona Vanilde: Benzia sim, e morria na hora. Falei, amanhã ele benzeu, 'amanhã torno a benzer'. Aí outro dia bem cedo ele chegou no clarear do dia e falou 'Ah, esse aqui foi boca de capanga', Aí falou para o guri 'você pode ir lá que está tudo lá, não escapava não, morria mesmo a cobra. Tudo que ele benzia morria, num tinha boca, não $o^{11}$.

Os conhecimentos de Manezinho sobre "arrumação" e benzeção são agenciados para curar pessoas ou para lançar algum feitiço a outrem. Assim, a pessoa que detém o conhecimento de benzeções e "arrumação" não se descola da participação na produção das festas de santo, pois Manezinho realizava festa

${ }^{11}$ Entrevista realizada com Dona Vanilde em dezembro de 2012. 
de Nossa Senhora da Guia, além de compartilhar os alimentos produzidos pela sua roça com a vizinhança.

Interessante destacar que, de acordo com Vanilde, Manezinho teria aprendido a "ruindade" no livro de São Cipriano, isto é, saberes externos aos herdados de seus ancestrais. Não encontrei o livro em Lagoinha de Cima, mas ele é mencionado em algumas narrativas, como fonte de feitiços que "faz ruindade com as pessoas", novamente o sentido de maldade é colocado como algo diverso dos conhecimentos locais. O livro de São Cipriano é uma coletânea de rituais mágicos com diversas finalidades. Popularmente conhecido como um livro de magia negra é identificado em Lagoinha de Cima como um livro de "feiticeiro, pra fazer coisa ruim".

Pode-se afirmar que determinadas situações são interpretadas como resultado de intervenções mágicas. Afetar os corpos humanos, vegetais e animais é também um meio de resolução de conflitos familiares e disputas de terras no interior da comunidade, baseado em saberes que algumas pessoas possuem, tal como o acontecimento descrito de briga entre irmãos, motivada por sovina (prática que contraria os valores ali compartilhados: o mutirão, o compartilhamento de alimentos, etc), onde o irmão teria colocado uma lacraia na perna de sua irmã. Este bicho arrumado causou-lhe um inchaço na perna até que, ofendida por esse e outros ataques, decidiu morar em Cuiabá.

Ainda que haja um sentido de unidade estabelecido, ela não é homogênea. Envolve tensões internas ajustadas constantemente entre as pessoas e suas perspectivas. Este ajuste se realiza de diversas maneiras, sendo as práticas de "arrumação" e benzeção mediadores, e neste aspecto guardam uma semelhança com os santos. Ao mediarem as relações entre as pessoas, incluem também parceiros que colaboram neste processo: são eles os corpos vegetais, animais e espíritos como o Camboni e a Vovozinha.

Plantas como a arruda, "mau-olhado" e "só-levanta" são utilizadas em banhos para a proteção contra "arrumação" e benzeções, ou como agentes curadores de doenças e infortúnios delas decorrentes. Os conhecimentos botânicos sobre a diversidade ali presente são reconhecidos como importantes práticas terapêuticas concomitantes ao uso de remédios alopáticos. Seu uso está entremeado por concepções cosmológicas sobre interferências "indiretas" deste plano invisível, uma vez que não são realizadas face a face.

Na realização de uma "arrumação", algumas pessoas têm seus protetores, parceiros, ou seja, auxiliares que circulam por este plano invisível, que em Lagoinha de Cima foram identificados como Camboni e a Vovozinha. Estes sujeitos são considerados agentes vinculados ao "lado do mal", acionados para prejudicar outrem. De acordo com Seu João os benzedores também possuem os seus parceiros, com quem conversam durante a benzeção. Eles auxiliam-no a retirar da pessoa o mal sofrido como nos casos de quebrante e mau olhado.

Para as pessoas de Lagoinha de Cima, o quebrante e o mau olhado, são causados pela pessoa com "sangue quente", que gera um mal ao outro ainda que involutariamente.

Aos objetos é atribuída a qualidade de portador e transmissor da força de seu proprietário, por isso é possível benzer alguém a partir do contato com algum objeto pessoal. Os benzedores são reconhecidos localmente como pessoas dotadas de conhecimentos herdados de gerações anteriores, especialmente aqueles relacionados à manipulação de plantas para banhos ou chás a serem consumidos pelos enfermos. 
ACENO, Vol. 3, N. 6, p. 71-86. Ago. a Dez. de 2016. ISSN: 2358-5587.

Cosmologias, territorialidades e políticas de quilombolas e de povos tradicionais (dossiê).

Aqueles que detém esse conhecimento experimentam uma condição liminar expressa pelas acusações latentes de feitiçaria. Seus conhecimentos podem ser utilizados para múltiplas finalidades, como afirma Turner (2005, p. 186): "Os curandeiros [...] são frequentemente temidos, do mesmo modo que são invocados, pois são verdadeiros 'curandeiros-bruxos' que combatem os ataques daqueles que usam magia negra contra os seus parentes e vizinhos”.

\section{Considerações finais}

Outras etnografias (FÉLIX, 2011; VIEIRA, 2015) destacam que a vida social cotidiana em diferentes comunidades quilombolas como em Serrinha, localizada no Baixo-Amazonas, município de Oriximiná, no estado do Pará, e na Malhada, situada no Alto Sertão do Caetité, estado da Bahia, respectivamente, são constituídas por práticas de cura como as benzeções que protegem contra as "porcariadas", os "feitiços" e "as coisas ruins". O estudo de Eduardo Galvão (1955, p.06) já havia ressaltado que a "vida religiosa" dos "caboclos" da região do Baixo-Amazonas estavam organizadas de um lado, pelas irmandades religiosas de culto aos santos e de outro, pela existência de seres não-humanos como currupiras, bichos visagentos, mães de bicho, seres encantados e a "panema", a força mágica com o poder de alterar as habilidades dos indivíduos em suas práticas de caça, pesca e bem-estar. Longe de afirmar que as benzeções e as "arrumação" praticadas em Lagoinha de Cima sejam uma exclusividade quilombola, em tudo parece apontar que para as comunidades quilombolas e outros povos tradicionais, a vida social é feita de relações e agenciamentos entre seres humanos e seres não-humanos, ou seja, de acontecimentos intensivos que exigem uma constante busca por rearranjar e reestabelecer a ética e a estética de seus modos de existência.

As concepções e experiências identificadas em Lagoinha de Cima e a existência de seres não-humanos como o troá, o boitatá e o lobisomem (em sua potência metamórfica e monstruosa), assim como a agência de determinados animais que são "mandados" por "arrumação", podem indicar uma percepção análoga aquela onde a 'qualidade de perspectiva' (VIVEIROS DE CASTRO, 2002b) não é exclusiva aos humanos. Em outras palavras, ao apontar que a "qualidade perspectiva" não é exclusiva dos humanos seria possível arriscar que esta não seria exclusiva do pensamento ameríndio, e quando contrastadas a outros modos de pensamento pode indicar novas questões.

Os seres não-humanos, benzeções, "arrumação" e santos constituem a cosmologia deste coletivo por isso são tratados com seriedade, o que impede de classificá-los como lendas folclóricas que nada dizem sobre a vida social ou fantasias desprovidas de significado ou "realidade". Um caminho possível de compreensão deste modo de existência é pensar que os territórios quilombolas, mas não exclusivamente eles, implicam "universos de referências, cognitivos, afectivos, estéticos" de "territórios existenciais" nos quais há fluxos contínuos e acontecimentos cujas intensidades como as feitiçarias e as benzeções dizem mais sobre os processos de subjetivação destes coletivos e de sua forma de "apreensão do mundo" (GUATTARI, 1992). 


\section{Bibliografia}

AUSTIN, J. L. Quando Dizer É Fazer. Palavras e Ação. Porto Alegre: Artes Médicas, 1990.

BRASIL. Constituição da República Federativa do Brasil de 1988. Brasília (DF).

CARDOSO, Vânia Z. "Narrar o mundo: estórias do "povo da rua" e a narração do imprevisível”. Mana. Rio de Janeiro, v. 13, n 2. 2007. p. 317-345.

CARNEIRO DA CUNHA, Manuela. Cultura com Aspas. São Paulo: Cosac Naif, 2009.

COELHO de SOUZA, Marcela Coelho de. "Parentes de sangue: incesto, relação e substância no pensamento indígena Timbira”. Mana. Rio de Janeiro, v. 10, n.1, 2004, p.25-60.

DELEUZE, Gilles e GUATTARI, Félix. Mil Platôs. Capitalismo e Esquizofrenia Vol. 5. Rio de Janeiro: Editora 34. 1995.

FAVRET-SAADA, Jeanne. "Ser afetado". Cadernos de campo. n. 13. p. 155-161, 2005 .

FÉLIX, Camila Corrêa. "Eles são cristãos como nós”. Humanos e encantados numa comunidade negra amazônica. Dissertação de Mestrado. UFRJ/Programa de Pós-Graduação em Antropologia e Sociologia, 2011.

GALVÃO, Eduardo. Santos e Visagens. Um estudo da vida religiosa de Ita Baixo Amazonas. São Paulo: Companhia editorial Nacional, 1955.

GEERTZ, Clifford. A interpretação das culturas. Rio de Janeiro: Zahar Editores, 1989.

GUATTARI, Félix. Caosmose. Um novo paradigma estético. São Paulo: Ed. 34, 2008.

LÉVI-STRAUSS, Claude. O Pensamento Selvagem. São Paulo: Papirus, 1989.

MALUF, Sonia Weidner. "Além do templo e do texto: desafios e dilemas dos estudos de religião no Brasil”. Revista Antropologia em primeira mão. Florianopólis, v. 124, 2011, p. 5-14.

OSÓRIO, Patrícia Silva. "Os festivais de cururu e siriri: mudanças de cenários e contextos na cultura popular”. Anuário Antropológico. Brasília, v. 1, n. 1, 2012 p. 237-259.

PORTO, Liliane. A Ameaça do Outro: Magia e Religiosidade no Vale do Jequitinhonha (MG). São Paulo: Attar, 2007. 
RADCLIFFE-BROWN, A. R. "Introdução". In: RADCLIFFE-BROWN, A. R. \& FORDE, D. Sistemas políticos africanos de parentesco e casamento. Lisboa: Calouste Gulbenkian, 1982, p. 59-161

- "Nota adicional sobre os parentescos por brincadeira". In: Estrutura e função na sociedade primitiva. Petrópolis: Vozes, 2013.

"Os parentescos por brincadeira". In: Estrutura e função na sociedade primitiva. Petrópolis: Vozes, 2013.

SAÉZ, Oscar Calavia. "O que os santos podem fazer pela antropologia?” Religião e Sociedade. Rio de Janeiro, v. 29, n. 2, 2009, p. 198-219.

SAHLINS, Marshall. "O "pessimismo sentimental” e a experiência etnográfica: Por que a cultura não é um “objeto" em vias de extinção (PARTE I)". Mana. v. 3, n. 1, 1997, p. 41-73.

SILVA, Renata Bortoletto \& GIANOTTI, Simone. Relatório de Caracterização Sócio-Histórica e Antropológica Associação Quilombola Comunidade Negra Rural Lagoinha de Baixo, Chapada dos Guimarães (MT). Instituto de Colonização e Reforma Agrária (INCRA), Superintendência Regional de Mato Grosso SR/13, Cuiabá, MT, março de 2007.

SILVA, Danielli Katherine Pascoal. Cosmologia quilombola: entre arrumações, benzeções e seres não-humanos. Trabalho de Conclusão de Curso (Graduação em Ciências Sociais) - Universidade Federal de Mato Grosso, 2014.

TURNER, Victor. Floresta de símbolos - Aspectos do ritual Ndembu. Niterói: EDUFF. 2005.

VIEIRA, Suzane de Alencar. Resistência e Pirraça na Malhada. Cosmopolíticas Quilombolas no Alto Sertão de Caetité. Tese de Doutorado. Antropologia. UFRJ/Museu Nacional, 2015.

VIVEIROS DE CASTRO, Eduardo. “O nativo relativo”. Mana. Rio de Janeiro, v. 8, n. 1, 2002a, p. 113-148. . A inconstância da alma selvagem. São Paulo: Cosac Naify. $2002 b$.

"Perspectival Anthropology and the Method of Controlled Equivocation”. Tipití, 2004, p. 3-22.

WAGNER, Roy. A invenção da cultura. São Paulo: Cosac Naify. 2010.

Recebido em 20/11/2016. Aprovado em 20/12/2016. 